\title{
An Innovative Approach to Produce Soil-Based Building Products
}

Soil has been used as a building material in different forms, such as mud, adobe, rammed earth, and bricks. Compressed Stabilized Earth Block (CSEB), a form of soil blocks with different additives including cement, fly ash, and lime, is a sustainable building material with many advantages compared to other conventional building materials. The usual practice of past researchers in producing CSEB was to add different materials like sand to the soil to control its clay and silt (finer) content. A high level of finer content is not desirable when it comes to the strength and durability of CSEB. This study proposes to reduce/ extract the finer content in the soil by washing it using a conventional concrete mixing machine.

The concept of particle packing optimization was suggested to modify the soil grading to produce CSEB, so that strength and durability properties can be enhanced. The study also proved that CSEB can be produced using the conventional cement block making machine with this soil modification process.

Soil washing process ended up with residual finer content that could be used for other soil-based building materials such as burnt-bricks and roof tiles. The study outcomes recommend the production of burnt-bricks and roof tiles with the extracted finer content mixed with fly ash. Fly ash is an industrial waste that causes many environmental issues. Therefore, the method suggested through this study has environmental benefits as well.

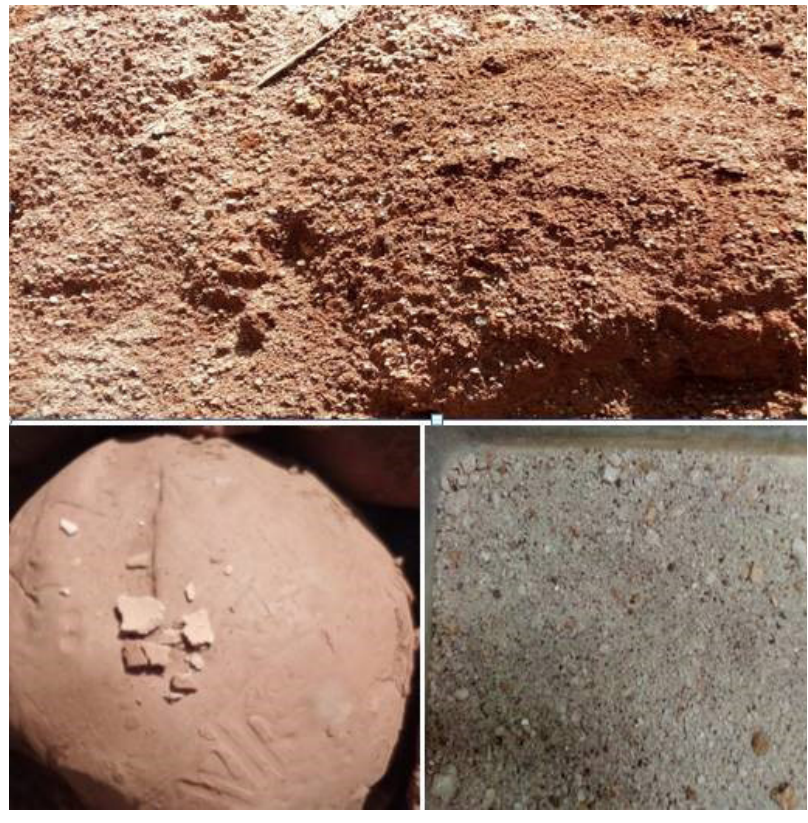

Used soil, Separated Finer and Gravel

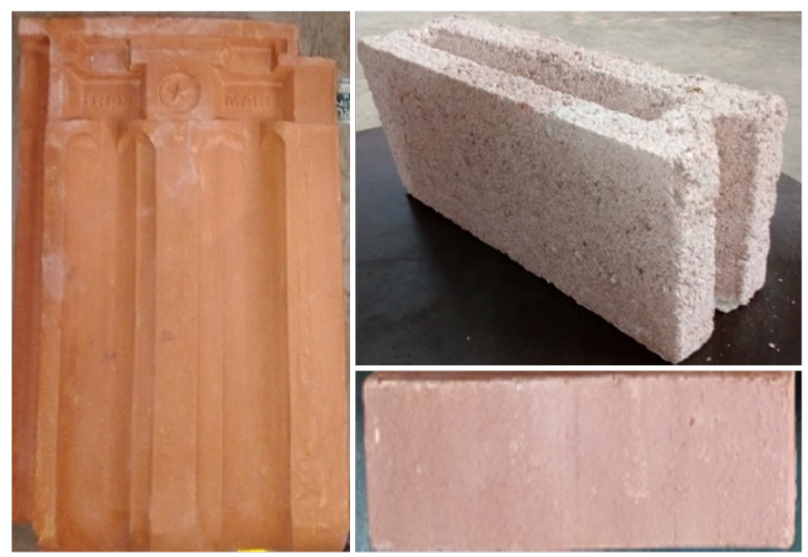

Innovative soil-based products 


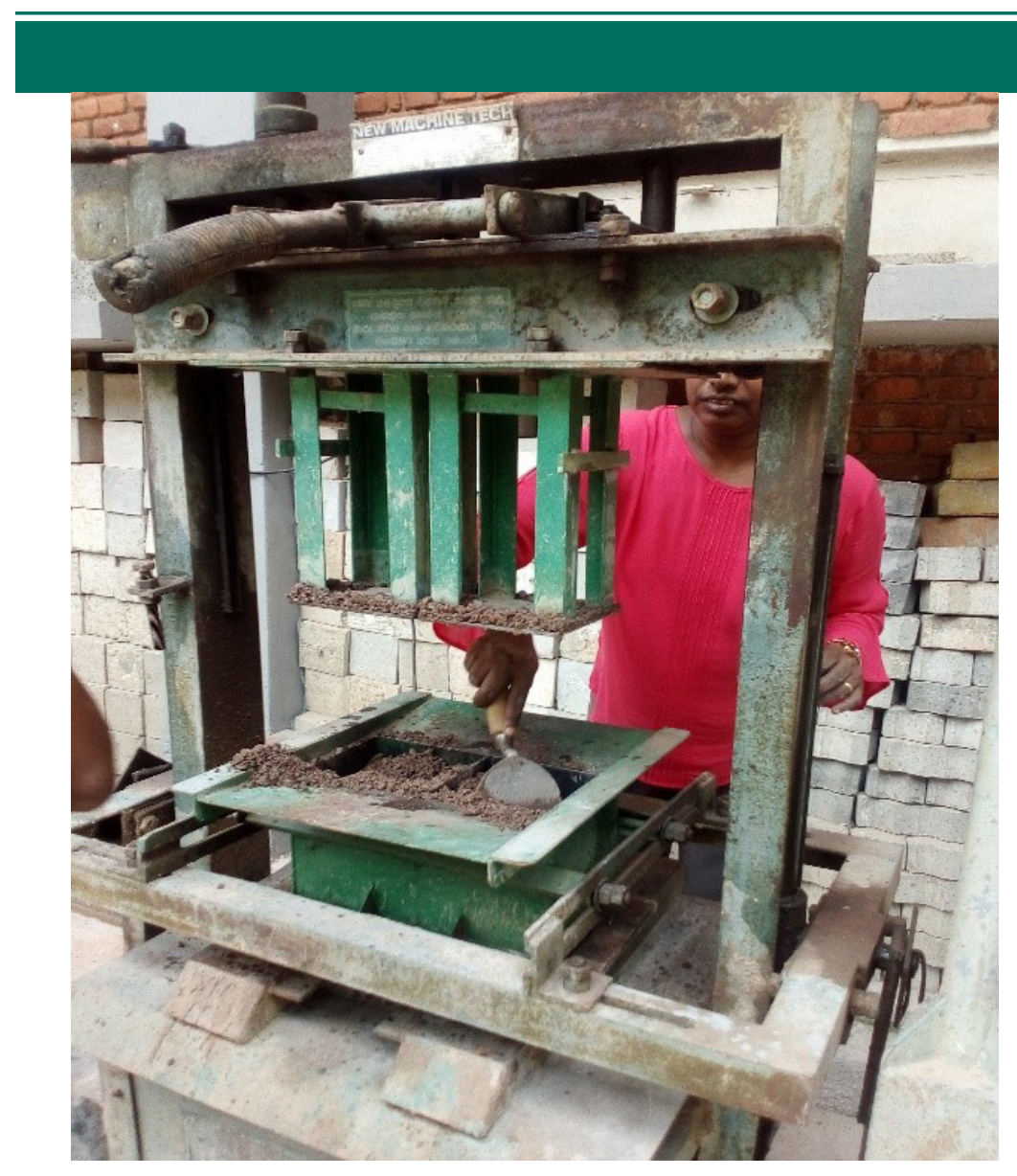

Research Highlights

$<$ Use of Block Making Machine for CSEB Production

The cost analysis of blocks showed that the production cost of a block is around Rs. 35.00. Compared to the average selling price of cement blocks available in the market, around $20 \%$ profit can be secured from this innovative soil blocks. A significant cost reduction in the production of roof tiles and bricks can also be achieved.

Finally, this study concluded that the soil washing process can be used to separate the finer particles and the coarse particles to produce sustainable building materials through an innovative integrated approach. With this process, waste and abundant soil can be utilized effectively by minimizing the adverse effect to the environment.

\section{Recently completed PhD}

Research Title

An Innovative Approach to Produce Soil-Based Building Products

Candidate Name:

S.N. Malkanthi

Supervisor:

Prof. Aoska Perera,

Department of Logistics and

Transport Management, Faculty of Engineering

Present occupation:

Senior Lecturer, Department of Civil and Environmental Engineering, Faculty of Engineering,

University of Ruhuna

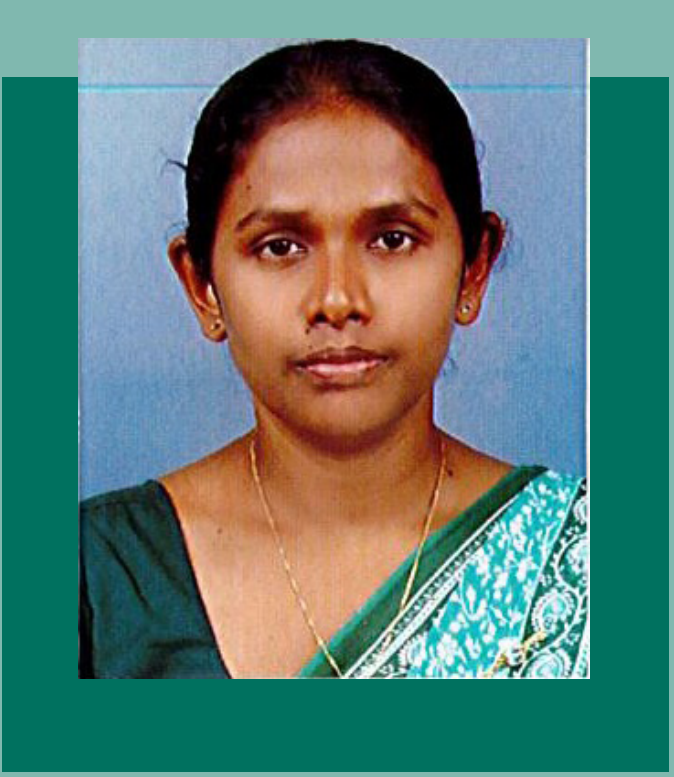

S.N. Malkanthi

PhD (completed), Department of Civil Engineering University of Moratuwa, 